Bull. Egypt. Soc. Physiol. Sci. 40(2), $136-153$

\author{
Bull. of Egyp. Soc. Physiol. Sci. \\ (Official Journal of Egyptian Society for Physiological Sciences) \\ (pISSN: 1110-0842; eISSN: 2356-9514)
}

\title{
Exogenous versus Endogenous Stem Cells Impacts on Knee Articular Cartilage Repair, Pain Sensation and Gait in A Rat Model of Osteoarthritis; Structural and Functional Assessment
}

\author{
Heba Makarem Sadek ${ }^{1}$, Horeya Erfan Korayem ${ }^{2}$, Shimaa Mohammad Yousof ${ }^{1,3}$, \\ Dalia Abd-Elhalim ${ }^{1}$ \\ ${ }^{1}$ Department of Medical Physiology, Faculty of Medicine, Suez Canal University, Ismailia \\ ${ }^{2}$ Department of Histology, Faculty of Medicine, Suez Canal University, Ismailia \\ ${ }^{3}$ Department of Medical Physiology, Faculty of Medicine, KAU, Rabigh, Saudi Arabia.
}

Received: 7 Nov 2019

Accepted: 31 Jan 2020

Available online: 1 Jan 2020

\section{Keywords}

- Articular cartilage

- Bone marrow derived mesenchymal stem cells

- Granulocyte colony stimulating factor

- Osteoarthritis

\section{Abstract}

Osteoarthritis (OA) is a joint disease with a very limited available curative option. Stem cells-based therapy revealed a promising regenerative capability in cartilage repair. We aimed to compare the sole and the combined effects of bone marrow derived mesenchymal stem cells (BM-MSCs) and the granulocyte colony stimulating factor (G-CSF) mobilized endogenous stem cells in articular cartilage repair, pain and gait improvement in monoiodoacetat (MIA)-induced rat model of osteoarthritis. OA was induced by a single intra articular injection $1 \mathrm{mg}$ MIA. BM-MSCs-treated and the combined groups received a single intra-articular of injection of BM-MSCs. G-CSFtreated and the combined groups received subcutaneous injections of G-CSF. The articular cartilage repair, total leucocytic count, nociception behavior and gait parameters were assessed. The results revealed an increase in total leucocytic count on the $5^{\text {th }}$ day after G-CSF injection and returned to normal on day 35. All treated groups showed comparable improvement in nociception behavior and gait parameters. Histopathological evaluation showed enhanced cartilage repair in the combined group compared to the two other treated groups. In conclusion The concomitant application of BM-MSCs and GCSF have a promising comparable effect of exogenous and mobilized endogenous stem cells on pain, gait and the structural improvements.

Corresponding author: : Dr. Shimaa Mohammad Yousof; Faculty of Medicine, Department of Medical Physiology, KAU, Rabigh, Saudi Arabia; Suez Canal University, Egypt Email: drshimaay@gmail.com, smabrahem@kau.edu.sa, Mob. \#: 


\section{INTRODUCTION}

Osteoarthritis is a complex disease affecting the whole joint as an organ (1). The disease is initiated by micro and macro injury that activates maladaptive repair response, and finally lead to molecular derangement followed by anatomic, and/or physiologic derangements (2). As being a main weight bearing joint in the body, knee OA accounts for $83 \%$ of the total burden of the disease (3).

$\mathrm{AC}$ is avascular and aneuronal highly specialized type of connective tissue that covers the bony ends forming the joint; chondrocytes are the unique cell type in the cartilage. Cartilage damage is the hallmark of OA, because this alters the homeostatic environment of the whole joint (4).

Intra articular injection of MIA causes inhibition of chondrocyte glycolysis, disturbance of the chondrocyte homeostasis and induction of chondrocyte death and matrix disruption with subsequent degeneration of $\mathrm{AC}$ and formation of subchondral bone lesions which mimic the histopathological changes that develop in human OA (5-7).

Till now, There is no approved curative treatment for the disease (8). All the available approaches cannot stop the progressive loss of joint tissues which leads finally to the need of total joint replacement (TJR) (9).

$\mathrm{AC}$ is a target for tissue engineering due to its avascular nature and poor capacity to heal spontaneously besides lacking a direct access to reparative cells. (10-14). BM-MSCs have the advantages of high chondrogenic and osteogenic differentiation potential with high proliferative activity $(15,16)$.
Recently, peripheral blood (PB) became a new candidate in cell based therapy research as it could be enriched with a valuable number of systemically mobilized precursor cells from the bone marrow under the effect of certain cytokine. G-CSF is a growth factor for hematopoietic stem cells proliferation and differentiation, it promotes the differentiation of cells into neutrophil lineage. Several studies revealed that, G-CSF also has a non-hematopoietic functions and promots MSCs mobilization from bone marrow to peripheral blood (17-19).

Therefore, this study was designed to investigate the effect of MSCs, G-CSF each of them individually as well as the combined effect of both on OA improvement in a rat model.

\section{Methods:}

\section{Study setting and ethical consideration:}

This study was carried out in physiology department and in the tissue culture unit, center of excellence; Faculty of Medicine, Suez Canal University. The protocol of this study was approved by the Ethics Committee, Faculty of Medicine; Suez Canal University, Egypt.

\section{Animals:}

Thirty adult male Albino rats weighing $200 \pm 50 \mathrm{gm}$ at the start of the experiment were randomly and equally divided into five groups: Group I: normal control group, Group II: OA group. Group III: BM-MSCs treated group; OA induction was followed by treatment with BMMSCs. Group IV: G-CSF treated group; OA induction was followed by treatment with G-CSF and, Group V: Combined treated group; OA induction was followed by treatment with both GCSF and BM-MSCs. All groups were studied for 4 
weeks after the establishment of $\mathrm{OA}$, then, were sacrificed by decapitation on day 35 .

\section{Induction of $\mathrm{OA}$ :}

All rats, except rats in group I, received MIA as follows: On day 0 (beginning of the study), rats were anesthetized with ketamine hydrochloride $(50 \mathrm{mg} / \mathrm{kg})$ and xylazine $(10$ $\mathrm{mg} / \mathrm{kg}$ ), to avoid pain sensation. The right knee was shaved and disinfected with $70 \%$ ethanol. A single dose of $50 \mu \mathrm{l}$ normal physiological saline containing $1 \mathrm{mg}$ MIA (Sigma-Aldrich, St. Louis, MO, USA) via a 27 gauge needle and a $1 \mathrm{ml}$ syringe was injected into the right knee joint through the infrapatellar ligament $(5,20,21)$. The site of intra-articular injection was located by feeling a depression between femur and tibia where a fluctuating white glistening infrapatellar ligament was felt. Then, both femur and tibia were brought to an angle of $90^{\circ}$ and MIA was injected into the joint space of the right knee with the needle of the syringe inserted for approximately 2 to $3 \mathrm{~mm}$ into the joint. For confirmation of proper administration of MIA into the joint cavity, two rats were used to induce osteoarthritis with MIA prior to the study. To ascertain proper procedure of intra-articular administration, blue dye was injected in the joint cavity, and then the joint was opened to ascertain its proper administration into joint space in the same two rats (22). Group I received an equivalent volume of normal physiological saline.

Administration of G-CSF: After establishment of osteoarthritis by MIA, group IV and V have received a single subcutaneous injections of 100 $\mu \mathrm{g} / \mathrm{kg} \quad$ G-CSF (Filgrastim) (SEDICO pharmaceutical co., 6 october city, Egypt) in 500 $\mu 1$ of normal physiological saline for 5 successive days, This dose mirrors clinical use of G-CSF and is commonly used within murine models to promote the mobilization of stem cells into peripheral blood (23).

\section{TLC for assessment of bone marrow stimulation}

by G-CSF: Peripheral blood samples were obtained from retro-orbital sinus of each rat in all study groups at Samples were obtained on day 0 , 12 ( $5^{\text {th }}$ day from G-CSF administration), 35 of the study, as on day 5 there is maximal increase of TLC as reported by a previous study (24). TLC was ssessed by automated cell counter.

Administration of BM-MSCs: After establishment of osteoarthritis by MIA, group III and V received a single dose of $1 \times 10^{6}$ BM-MSCs in $50 \mu$ of normal physiological saline as a vehicle (25). MSCs were administered intra articularly as described above.

\section{Collection, Preparation and labeling of BM-}

MSCs: Three adult male albino rats, weighing about 120 grams were used as a donor of bone marrow cells. Stem cells were isolated from the rat bone marrow under very restricted sterile conditions. After bone marrow flushing, cells were centrifuged at $1500 \mathrm{rpm}$, for 10 minutes and the supernatant was removed by aspiration. Cells were washed two times more by resuspending them into PBS and centrifuging them. Cells were resuspended in $10 \mathrm{ml}$ complete medium composed of Dulbecco's Modified Eagle's Medium (DMEM) supplemented with $10 \%$ fetal bovine serum (FBS) and $1 \%$ penicillin/streptomycin (PEN-STREP). 
The cells were seeded in a tissue culture dish containing complete culture medium and were incubated in a humidified atmosphere containing $5 \% \mathrm{CO} 2$, at $37^{\circ} \mathrm{C}$. Three days after seeding, the non-adherent cells were removed and the medium will be replaced with a fresh complete medium. The culture was monitored daily and the medium was changed every 3 days and cellular growth assessed daily under an inverted microscope. Within 7-10 days, the cells became confluent and the colonies were evident (adherent with fibroblastic morphology) when seen under inverted microscope, cells were harvested using $0.25 \%$ trypsin and $0.05 \mathrm{mmol} / \mathrm{l}$ EDTA (EthyleneDiamine-Tetra-Acetic Acid) and were counted using a hemocytometer (26).

MSC labeling was done by addition of superparamagnetic iron oxide (SPIO) contrast agent Sacrofer (iron succrose) with iron concentration $25 \mu \mathrm{g} \mathrm{Fe} / \mathrm{ml}$. Then, they were incubated in a humidified atmosphere containing $5 \% \mathrm{CO} 2$, at $37^{\circ} \mathrm{C}$ for 24 hours to allow uptake of ferumoxide by the cells. Following incubation and prior to trypsinizaion, MSCs were washed three times with PBS to remove any SPIO that had not been incorporated into the cells. Labeling were assessed histologically by Prussian blue staining (27).

\section{Behavioral Assessment:}

The following tests were done on days $0,3,7,14$, 21,28 and 35 of the experiment. Testing were performed blindly by the same experimenter. Rats were acclimatized to the testing situation for at least 1 week before the start of the experiment and
5 to $10 \mathrm{~min}$ before each testing until the exploration activity ceased (22).

\section{1) Pain assessment:}

a. Knee bend test: is used as an indicator of the animal nociception. It was carried out to evaluate the sensitivity of the normal range of movement and the movement-induced pain caused by MIA in the right knee. Starting with the knee in resting position (slightly flexed). The thigh was held and the knee was flexed and extended (within the physiological limits of knee flexion/extension). The test might cause some anxiety and pain in the rats and they would limit this by a response (struggle or squeak reaction). The number of squeaks (vocalizations) and/or struggle reactions in response to five alternate flexions and extensions of the knee joint for each rat was counted. The score of the test was determined as (0- no responses, 0.5- struggle to maximal flexion/ extension, 1- Struggle to moderate flexion/extension or vocalizations to maximal flexion/extension, 2- vocalizations to moderate flexion/extensions). The sum of the animal's reactions, giving maximal values of 20. A maximal extension corresponds to placing the knee joint in an $180^{\circ}$ angle; a moderate extension corresponds to an angle between $120^{\circ}$ and $150^{\circ}$, approximately; a moderate flexion corresponds to an angle between $45^{\circ}$ and $75^{\circ}$, approximately; a maximal flexion corresponds to totally bending the knee joint (corresponding approximately to an angle of $\left.30^{\circ}\right)$

b. Hot plate test: Used to detect thermal hyperalgesia and response of the injected knee to exposure to thermal stimulus. Rats were placed on the hotplate at $50 \pm 1{ }^{\circ} \mathrm{C}$ one at a time. The latency 
period for hind limb response (e.g., shaking, licking of the hind paw, or jumping off the plate in order to avoid the thermal stimulus) was recorded as response time. A latency period of $90 \mathrm{~s}$ was defined as complete analgesia and used as the cutoff time for rats that did not respond. Rats were removed from the hotplate immediately after a response observed (28).

\section{2) Gait analysis:}

Used for the detection of the functional assessment of the joint mobility, for evaluation of the consequences of $\mathrm{OA}$ in patients and in preclinical models. The paws of the rats were brushed with ink, Front paws and hind paws were colored with ink of different color. Immediately after ink application, rats were allowed to run on a $100 \mathrm{~cm}$ long, $20 \mathrm{~cm}$ wide Plexiglas track with white paper on the bottom with dark chamber present in the end of the track to entice the rats leaving their paw prints on blotting paper. From these paw prints, 5 parameters were measured: (Limb rotation: determined by the rotation angle between two consecutive paw prints; defined by a line through the incision of the paw print and the third phalanx. Step width: determined by the distance between a print from the left paw and a consecutive print from the right paw and vice versa (left- right or right-left-distance, respectively). Right stride length: determined by the distance between two constitutive right paw prints. Right step length: determined by the distance between constitutive right and left hind paw prints. Left step length: determined by the distance between constitutive left and right hind paw prints). For each animal and testing day, at least five artifact-free gait cycles (four consecutive prints) were analyzed and means of these values were used for further analysis (29).

\section{Histological Assessment:}

Animals were euthanized and the right knee joints were dissected and processed for further histological evaluation. Samples were fixed in buffered formalin for 2 days then in 10\% EDTA solution for two weeks. The solution was changed every three days until softening of the samples is obtained. Samples were embedded in paraffin. For each block, a minimum of ten slides with at least three samples of tissue per slide was obtained to minimize sampling errors. Samples were obtained from the center of the medial condyle as being the mechanical weight bearing area. Prior to staining the paraffin was removed by immersing the slides for two minutes in xylene and ethanol solutions. Slides were divided equally for staining Haematoxylin-eosin (H\&E) for assessment of cellular architecture and, Toluidine blue (T.B) for assessment of AC thickness. Histological assessment was carried out by two independent observers who were blinded to the study groups. A qualitative histological assessment under light microscopy was done using $5-\mu \mathrm{m}$ thick sagittal sections assessing surface irregularity, Chondrocytes and detection of newly formed hyaline like fibers. Quantitative assessment was done on $7 \mu \mathrm{m}$ thick toluidine blue stained sections using image J-based analysis system to assess the thickness of the cartilage.

\section{Statistical analysis:}

Data were analyzed using Statistical Package for Social Science (SPSS) for WINDOWS software, version 24. Data were presented as mean \pm SD. One way analysis of variance (ANOVA) 
was used for comparing means of a variable in all groups to determine if there is significant difference among several groups and tukey posthock test was used to compare groups using one of them as a control. $\mathrm{P}$ value $<0.05$ was considered statistically significant.

\section{Results:}

On day 0 (before MIA injection), there were no significant differences in parameters of pain behavior, gait parameters and TLC among different study groups.

\section{Behavioral assessment:}

1) Pain assessment:

\section{Knee bend test:}

On day 3 and up to day 7, the score was significantly higher in all groups $(\mathrm{P}$ value $=0.000)$ compared to the normal group. In O.A group, the score remained significantly higher till day 35 (P value $=0.000)$ compared to the normal group. The score of BM-MSCs treated group remained significantly lower than that of the OA group (P value $=0.007)$ till day 35 . The score of G-CSF treated group was significantly higher than that of the normal group $(\mathrm{P}$ value $=0.04)$ till day 35 . The score of the combined group remained significantly higher than that of the normal group $(\mathrm{P}$ value $=0.002)$ till day 28; Table (1)

Table (1): Knee Bend Score Throughout the Study

\begin{tabular}{|c|c|c|c|c|c|c|c|}
\hline & Day zero & Day 3 & Day 7 & Day 14 & Day 21 & Day 28 & Day 35 \\
\hline $\begin{array}{l}\text { Group I } \\
\text { (Normal) }\end{array}$ & $0.33 \pm 0.41$ & $\begin{array}{l}1.75 \pm \\
0.52\end{array}$ & $0.17 \pm 0.26$ & $\begin{array}{l}0.17 \pm \\
0.26\end{array}$ & $\begin{array}{l}0.17 \pm \\
0.26\end{array}$ & $\begin{array}{l}0.17 \pm \\
0.26\end{array}$ & $0.33 \pm 0.41$ \\
\hline $\begin{array}{l}\text { Group II } \\
(\mathrm{O} . \mathrm{A})\end{array}$ & $0.42 \pm 0.38$ & $\begin{array}{l}11.92 \pm \\
1.59 * * \\
\end{array}$ & $\begin{array}{l}11.83 \pm \\
2.06 * *\end{array}$ & $\begin{array}{l}10.75 \pm \\
1.13 * *\end{array}$ & $\begin{array}{l}9.08 \pm \\
3.62 * *\end{array}$ & $\begin{array}{l}6.5 \pm \\
3.02 * *\end{array}$ & $\begin{array}{l}6.67 \pm \\
3.66 * * \\
\end{array}$ \\
\hline $\begin{array}{l}\text { Group III } \\
\text { (BM-MSCs) }\end{array}$ & $0.33 \pm 0.41$ & $\begin{array}{l}13.75 \pm \\
1.60 * *\end{array}$ & $\begin{array}{l}11.75 \pm \\
02.11 * *\end{array}$ & $\begin{array}{l}4.73 \pm \\
1.51^{* \# \#}\end{array}$ & $\begin{array}{l}3.67 \pm \\
2.58 \#\end{array}$ & $\begin{array}{l}1.92 \pm \\
1.11 \#\end{array}$ & $\begin{array}{l}2.08 \pm \\
1.11 \#\end{array}$ \\
\hline $\begin{array}{l}\text { Group IV } \\
\text { (G-CSF) }\end{array}$ & $0.33 \pm 0.41$ & $\begin{array}{l}13.82 \pm \\
3.43 * *\end{array}$ & $\begin{array}{l}10.08 \pm \\
2.76 * *\end{array}$ & $\begin{array}{l}6.75 \pm \\
1.60 * * \#\end{array}$ & $\begin{array}{l}4.08 \pm \\
1.98 * \#\end{array}$ & $\begin{array}{l}4.10 \pm \\
0.84^{*}\end{array}$ & $3.92 \pm 1.50^{*}$ \\
\hline $\begin{array}{l}\text { Group V } \\
\text { (Combined) }\end{array}$ & $0.42 \pm 0.50$ & $\begin{array}{l}12.33 \pm \\
2.09 * *\end{array}$ & $\begin{array}{l}9.00 \pm \\
1.95^{* *}\end{array}$ & $\begin{array}{l}6.17 \pm \\
3.20 * * \#\end{array}$ & $\begin{array}{l}4.33 \pm \\
2.09 * \#\end{array}$ & $\begin{array}{l}5.08 \pm \\
2.89 *\end{array}$ & $3.75 \pm 2.25$ \\
\hline
\end{tabular}

Values are expressed as mean $\pm \mathrm{SD}$. * significant $\mathrm{P}$ value $\leq 0.05$ compared to the normal group. ** highly significant $\mathrm{P}$ value $\leq 0.001$ compared to the normal group. \# significant $\mathrm{P}$ value $\leq 0.05$ compared to O.A group. \#\# highly significant $\mathrm{P}$ value $\leq 0.001$ compared to O.A group. O.A=Osteoarthritis; BM-MSCs=Bone Marrow Mesenchymal Stem Cells; G$\mathrm{CSF}=$ Granulocyte Colony Stimulating Factor.

\section{Hot plate test:}

At day 3, the WL increased significantly in all groups compared to normal, except for the G-CSF. This significant increase lasted generally till day 14 (P value $\leq 0.05)$. At day 14 , The BMMSCs- \& G-CSF- treated groups and the combined group showed lower scores in the latency compared to the OA group ( $\mathrm{P}$ value $\leq$ 0.05). Yet, the G-CSF- treated group showed lower scores. By day 21, the combined group showed a lower score compared to the OA \& GCSF group. By day 35, the BM-MSCs score was higher compared to that of OA \& G-CSF groups; Table (2). 
Table (2): Hind Paw Withdrawal Latency (WL) Values (seconds) throughout the study

\begin{tabular}{|c|c|c|c|c|c|c|c|}
\hline & Day Zero & Day 3 & Day 7 & Day 14 & Day 21 & Day 28 & Day 35 \\
\hline $\begin{array}{l}\text { Group I } \\
\text { (Normal) }\end{array}$ & $5.07 \pm 0.75$ & $7.19 \pm 1.25$ & $\begin{array}{l}4.72 \pm \\
0.77\end{array}$ & $\begin{array}{l}3.55 \pm \\
0.50\end{array}$ & $\begin{array}{l}5.04 \pm \\
0.91\end{array}$ & $\begin{array}{l}5.31 \pm \\
0.54\end{array}$ & $\begin{array}{l}5.57 \pm \\
0.47\end{array}$ \\
\hline $\begin{array}{l}\text { Group II } \\
\text { (O.A) }\end{array}$ & $4.71 \pm 1.17$ & $19.68 \pm 4.39 * *$ & $\begin{array}{l}11.71 \pm \\
1.47^{* *}\end{array}$ & $\begin{array}{l}9.40 \pm \\
1.18^{* *}\end{array}$ & $\begin{array}{l}7.78 \pm \\
1.39 \\
\end{array}$ & $\begin{array}{l}4.27 \pm \\
0.76 \\
\end{array}$ & $\begin{array}{l}4.20 \pm \\
0.98 \\
\end{array}$ \\
\hline $\begin{array}{l}\text { Group III } \\
\text { (BM-MSCs) }\end{array}$ & $4.98 \pm 0.62$ & $15.11 \pm 4.13 * *$ & $\begin{array}{l}6.88 \pm \\
2.40 \#\end{array}$ & $\begin{array}{l}6.11 \pm \\
1.47^{* \#}\end{array}$ & $\begin{array}{l}6.65 \pm \\
2.87\end{array}$ & $\begin{array}{l}5.35 \pm \\
1.02\end{array}$ & $\begin{array}{l}6.32 \pm \\
1.77 \# \$\end{array}$ \\
\hline $\begin{array}{l}\text { Group IV } \\
\text { (G-CSF) }\end{array}$ & $5.22 \pm 1.89$ & $8.26 \pm 5.14 \# \#$ & $\begin{array}{l}8.30 \pm \\
3.31 * \\
\end{array}$ & $\begin{array}{l}4.27 \pm \\
1.63 \# \#\end{array}$ & $\begin{array}{l}7.70 \pm \\
2.19 \\
\end{array}$ & $\begin{array}{l}4.10 \pm \\
0.84 \\
\end{array}$ & $\begin{array}{l}4.10 \pm \\
0.63 \\
\end{array}$ \\
\hline $\begin{array}{l}\text { Group V } \\
\text { (Combined) }\end{array}$ & $3.86 \pm 0.92$ & $16.79 \pm 5.09^{* *}$ & $\begin{array}{l}7.39 \pm \\
1.08 \#\end{array}$ & $\begin{array}{l}6.78 \pm \\
1.72 * \# \$\end{array}$ & $\begin{array}{l}4.57 \pm \\
0.49 \# \$\end{array}$ & $\begin{array}{l}5.84 \pm \\
0.90 \# \$\end{array}$ & $\begin{array}{l}5.94 \pm \\
0.94 \$ \\
\end{array}$ \\
\hline
\end{tabular}

Values are expressed as mean $\pm \mathrm{SD}$. * significant $\mathrm{P}$ value $\leq 0.05$ compared to the normal group. ** highly significant $\mathrm{P}$ value $\leq 0.001$ compared to the normal group. \# significant $\mathrm{P}$ value $\leq 0.05$ compared to O.A group. \#\# highly significant $\mathrm{P}$ value $\leq 0.001$ compared to O.A group. $\$$ significant $\mathrm{P}$ value $\leq 0.05$ compared to G-CSF group. O.A=Osteoarthritis; BMMSCs=Bone Marrow Mesenchymal Stem Cells; G-CSF=Granulocyte Colony Stimulating Factor.

\section{2) Gait analysis:}

\section{Limb rotation:}

On day 7 , the angles were significantly higher in BM-MSCs treated group, combined group ( $\mathrm{P}$ value $\leq 0.05)$, in $\mathrm{OA}$ group and $\mathrm{G}-\mathrm{CSF}$ treated group $(\mathrm{P}$ value $\leq 0.001)$ compared to the normal group. By day 35, the angle significantly decreased in G-CSF treated group ( $\mathrm{P}$ value $\leq$ 0.001) and in BM-MSCs treated and combined group $(\mathrm{P}$ value $\leq 0.05)$ compared to $\mathrm{OA}$ group, while angles of the $\mathrm{OA}$ group remained significantly higher than that of the normal group $(\mathrm{P}$ value $\leq$ 0.001) $($ Fig. 1)

\section{Step width:}

On day 7 , there was a significant increase in the step width in BM-MSCs treated group (P value $\leq$ 0.001), in O.A group, G-CSF treated group and combined group $(\mathrm{P}$ value $\leq 0.05)$ compared with normal group. By day 35, step width significantly decreased in BM-MSCs treated group and combined group $(\mathrm{P}$ value $\leq 0.05)$ compared to the OA group (Fig. 2).

\section{Right stride length:}

On day 35 , the length was significantly lower in the OA group ( $\mathrm{P}$ value $\leq 0.05)$ when compared to the normal group, and significantly higher in all treated groups $(\mathrm{P}$ value $\leq 0.05)$ when compared with the OA group (Fig. 3).

\section{Right step length:}

On day 7 , there was a significant decrease in the length in OA group, BM-MSCs group, combined group $(\mathrm{P}$ value $\leq 0.05)$ and $\mathrm{G}$ CSF group $(\mathrm{P}$ value $\leq 0.001)$ compared to the normal group. On day 35, the length of all treated groups showed a significant increase ( $\mathrm{P}$ value $\leq$ 0.001) compared to O.A group (Fig. 4).

\section{Left step length:}

The left step length showed non-significant increase in some groups over the study duration compared to the normal control group (Fig. 5).

\section{A) TLC:}

The TLC was significantly higher on the $5^{\text {th }}$ day of G-CSF administration in G-CSF treated group and in the combined group compared to the normal 
group ( $\mathrm{P}$ value $\leq 0.02,0.03$; respectively). TLC in these groups returned to the normal on day 35 . TLC in OA group was significantly lower than the normal group on day 35 ( $\mathrm{P}$ value $\leq 0.01)$, as shown in (Fig. 6)

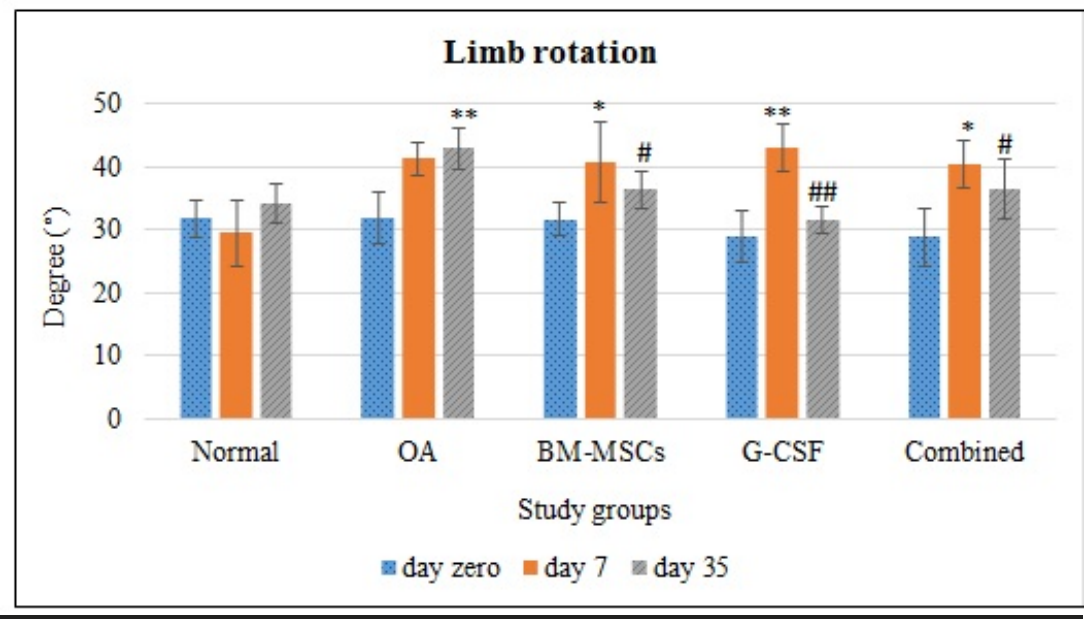

Figure (1): Limb rotation $\left({ }^{\circ}\right)$ at three different time points throughout the study.

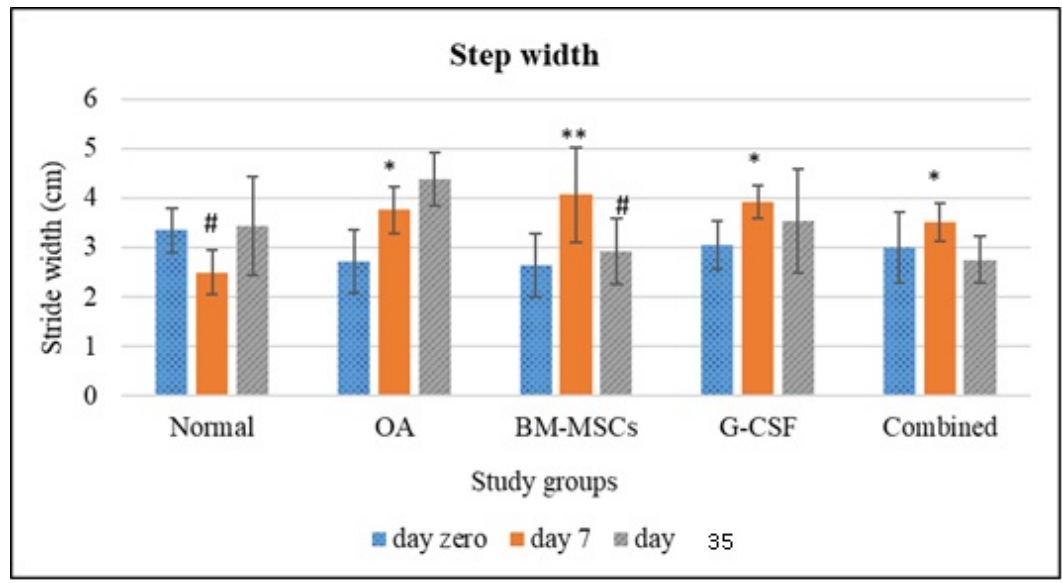

Figure (2): Step width $(\mathrm{cm})$ at three different time points throughout the study

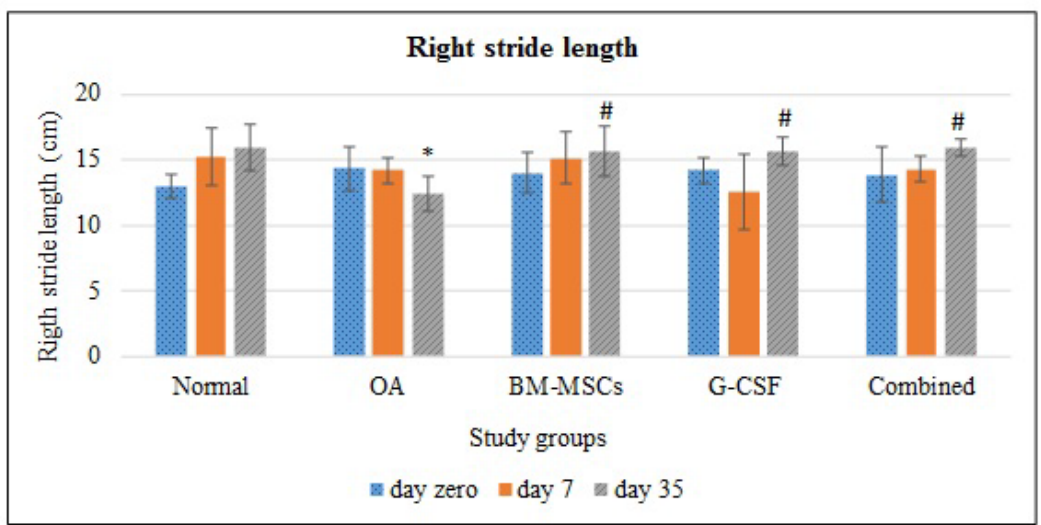

Figure (3): Right stride length $(\mathrm{cm})$ at three different time points throughout the study 


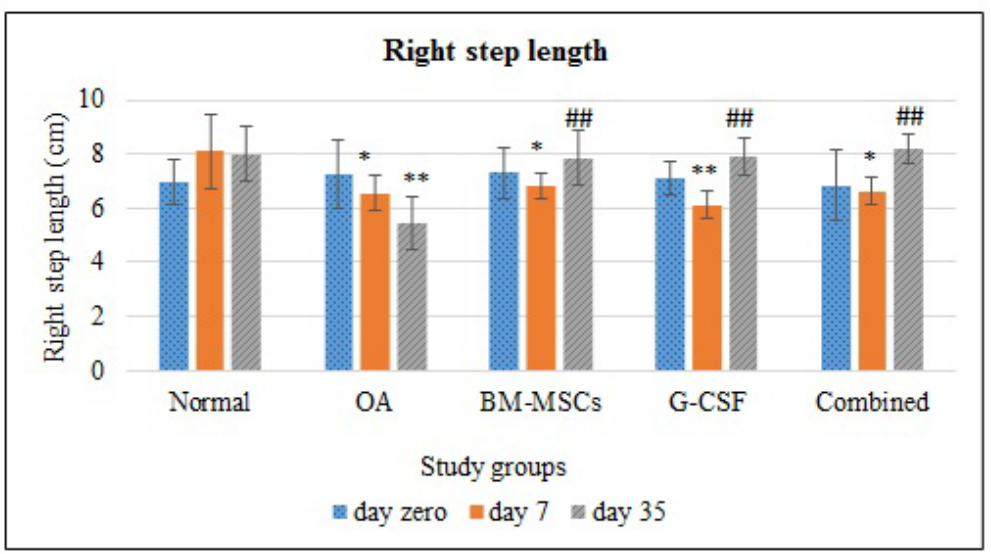

Figure (4): Right step $(\mathrm{cm})$ at three different time points throughout the study

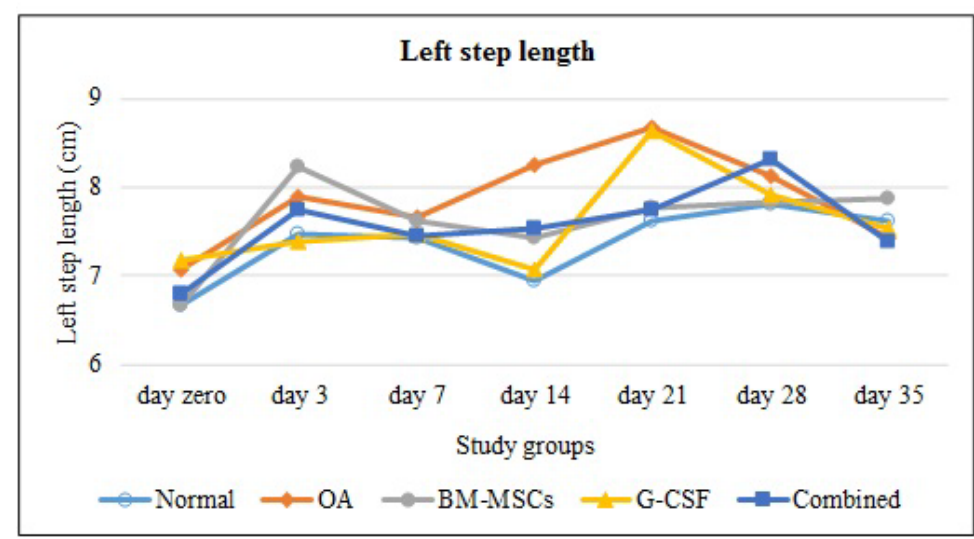

Figure (5): The change in left step length $(\mathrm{cm})$ among study groups over the study duration.

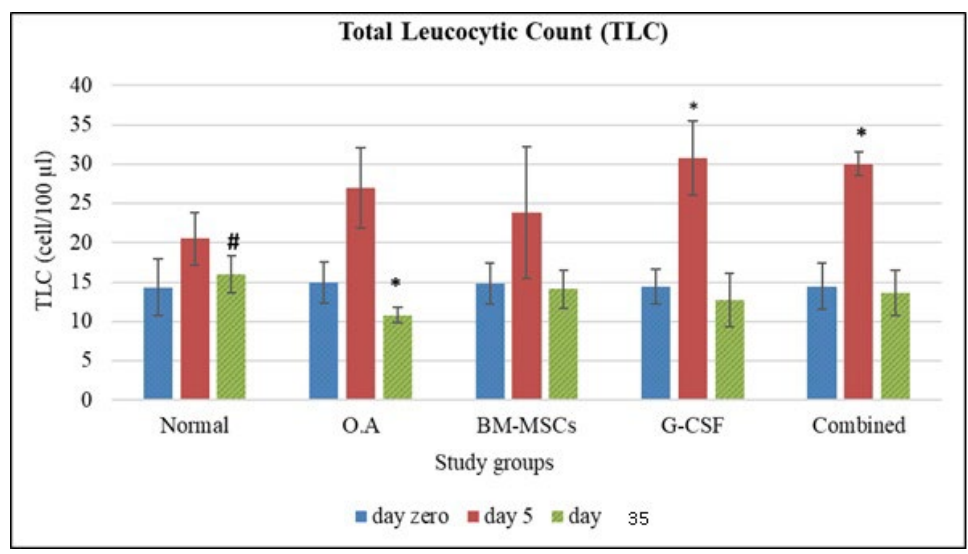

Figure (6): Chart shows peripheral blood TLC at three different time points of the study.

\section{B) Histopathological examination:}

Knee joints were examined histologically to assess the interrelation between joint pathology and the degree of nociception, and to evaluate the effect of the different administered treatments on restoration of the structural integrity of the affected joint. Control group; showed normal joint space and $\mathrm{AC}$ structure with homogenous and diffuse distribution of collagen fibers. There was a normal distribution and orientation of the four zones of the AC (Fig. 7). OA control group; revealed MIA induced degradation of the $\mathrm{AC}$ with loss of its structural integrity. These alterations in the AC surface caused a great narrowing of the joint space up to its obliteration in some sections (Fig. 7). BM-MSCs group; showed a reduction in the 
degenerative changes with the appearance of few regenerative signs in the $\mathrm{AC}$ as reflected by improvement in the surface irregularity with decreased fibrillations and erosions when compared to OA group (Fig. 8). G-CSF group; revealed a reduction in the degenerative changes as in BM-MSCs-treated group with formation of larger much more number of chondrocytes. The $\mathrm{AC}$ changes were incompletely reversed with

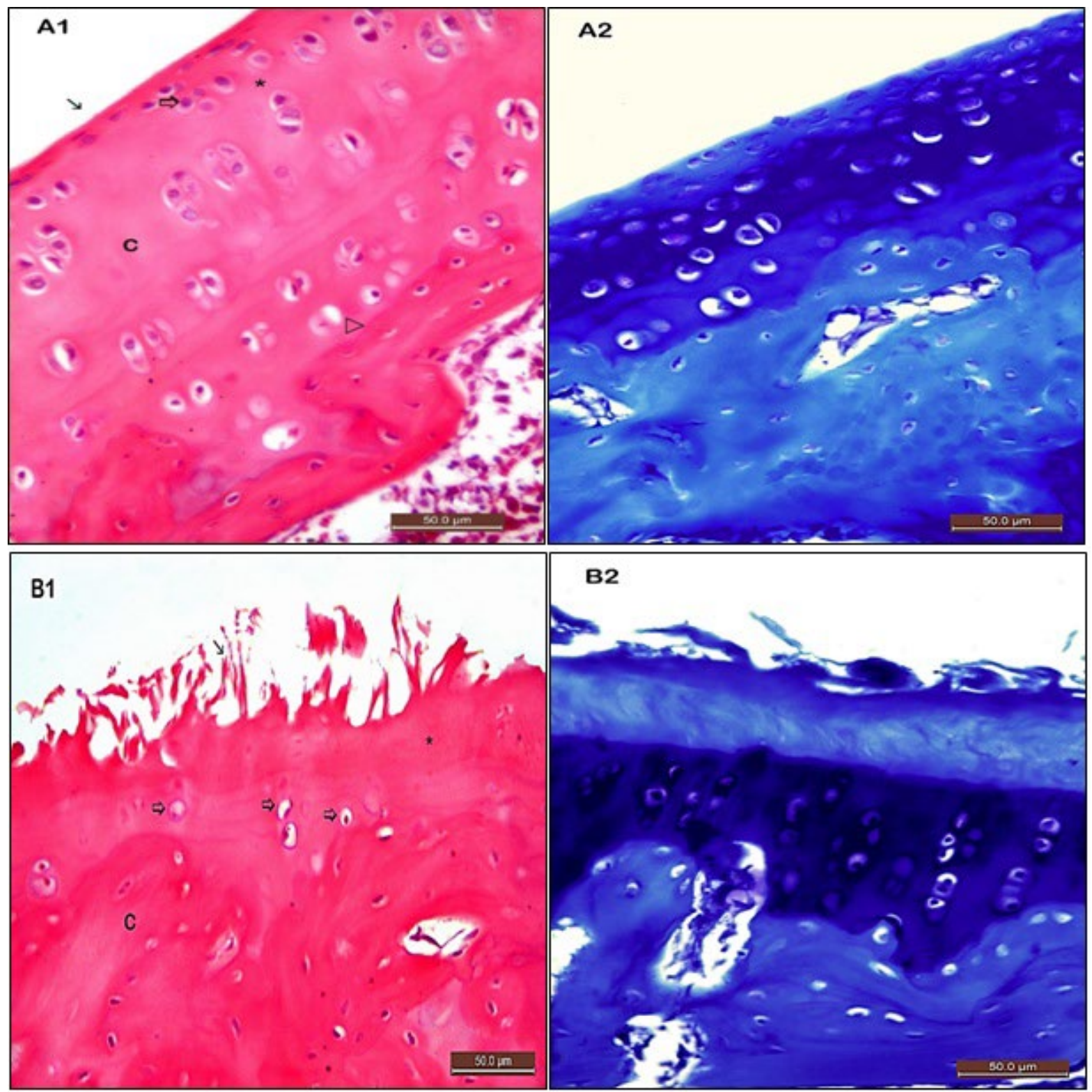

Figure (7): Photomicrographs of knee joint (Normal and OA groups) presence of few erosions and cracks in comparison to the normal control group (Fig. 8). Combined group; showed a good healing features in most of the specimens. The AC regained its smooth surface with no observed fibrillations or erosions. The surface lesions were replaced with hyaline or hyaline-like tissue with a good integration within the surface (Fig. 8). 

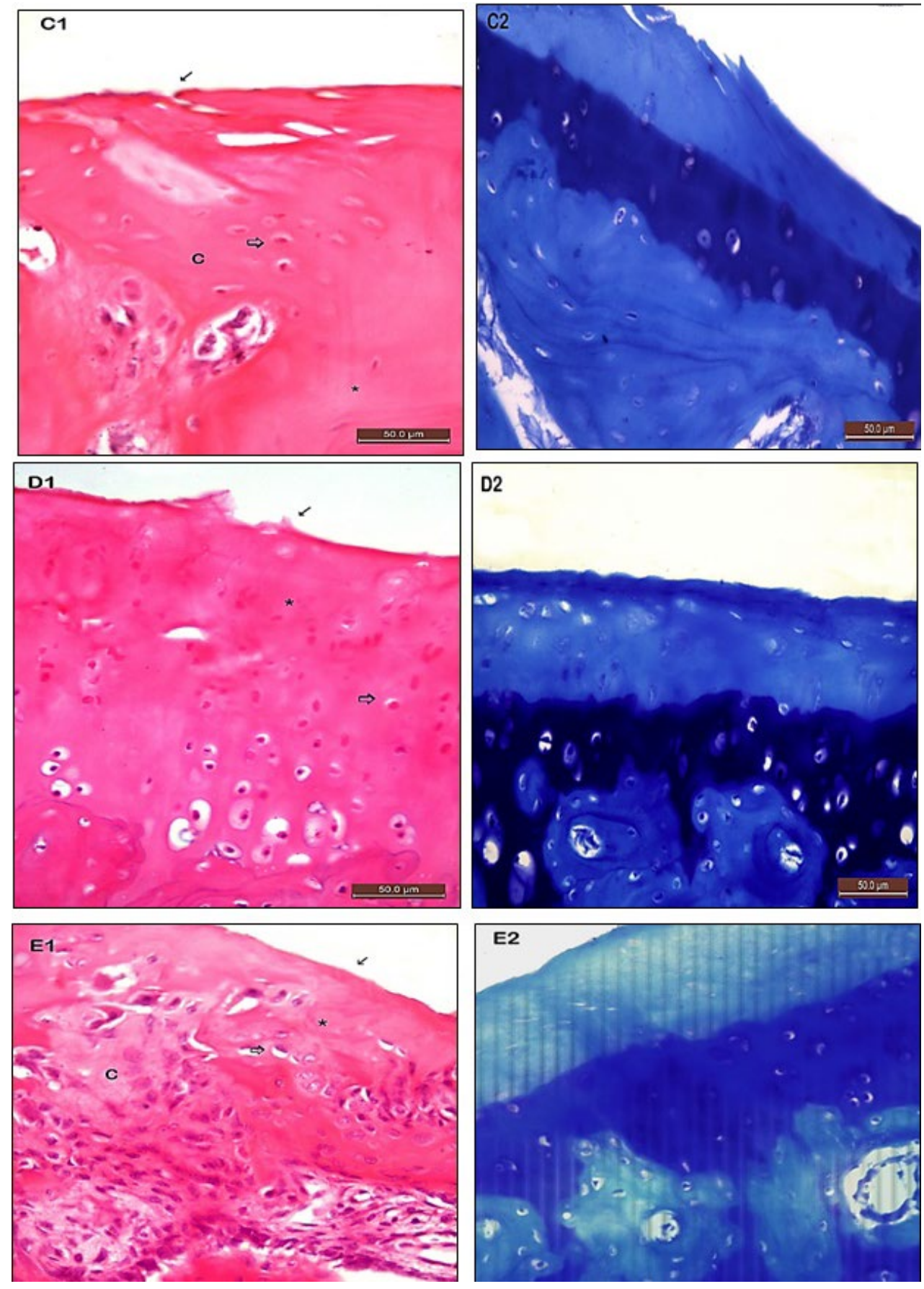

Figure (8): Photomicrographs of knee joint (BM-MSCs-treated group, G-CSF-treated group and combined groups)

\section{Discussion:}

In this study, we aimed at comparing the impacts of the sole and the combined use of BMMSCs and G-CSF on articular cartilage repair and behavioral improvement in MIA-induced rat model of OA. In this study, treatment with either BM-MSCs or G-CSF ameliorated the regenerative capacity of the AC and improved OA pain and gait behavior. Moreover, G-CSF administration has potentiated the effect of BM-MSCs with a better effect on structural and behavioral aspects.

The MIA model used in this study is a good one for evaluating OA pain, because it produce pain behavior comparable to that observed in OA patients (30) and also induce abnormal weight bearing and gait abnormalities like that 
observed in OA patients $(31,32)$. MIA starts to induce chondrocyte degeneration with necrosis and collapse of the articular cartilage layer as early as 1 day after its intra articular injection, this explains the early pain behavior that observed in this model (5).

In this study, a significant increase in TLC occurred in the $5^{\text {th }}$ day of G-CSF injection and TLC returned to normal on day 35. Similarly, Okano et al., (33) used G-CSF in an experimental osteochondral rat model to amplify the number of PB cells during the repair process and has found that TLC began to increase gradually from day 2 and this increase has returned to its original level after day 7. Sasaki et al., and Fu et al., $(34,35)$ reported that, the systemic administration of GCSF cause bone marrow stimulation and proliferation of the MSCs with detectable increase of MSCs in PB.

In this study, a microscopic examination of the knee joints revealed that MIA injection induce $\mathrm{AC}$ degeneration with a highly significant recession in AC thickness compared to the normal control group. These histopathological findings were in harmony with previous studies where they found a significant decrease in histopathological scores after MIA administration at different time points $(32,36,37)$.

In our work; we found that either treatment with BM-MSCs or G-CSF caused improvement of OA at the histopathological level as all observed findings occurred due to MIA injection were reversed with variable degrees in the study groups. Our results are in agreement with Sasaki et al., (34) who investigated the effect of low and high dose of G-CSF on repair of osteochondral defect in a rabbit model and they have reported an improvement in the histopathological score with formation of a thin layer of hyaline cartilage over the surface of the defect after 4 weeks. They related the improvement to the synergistic effect of bone marrow stimulation with G-CSF administration which induce MSC mobilization and migration to the site of injury with their proliferation and chondrogenic differentiation which was confirmed also in vitro. Fu et al., (35) reported that treatment with either G-CSF mobilized peripheral blood cells or BM-MSCs cause growth of transparent thin tissue in osteochondral defect in a rat model.

The effect of BM-MSCs on AC repair was examined previously in multiple studies on different OA models with a very promising outcome in AC regeneration $(25,38)$. Gupta et al., (39) found that intra-articular BM-MSCs causes regeneration of the cartilage with repair of $\mathrm{OA}$ changes in concomitant with reduction in OA pain. BM-MSCs possibly play a key role diminishing the pain induced by inflammation via secretion of numerous analgesic peptides and antiinflammatory cytokines with the effect of other bioactive factors that cause both decrease in inflammation and initiate $\mathrm{AC}$ regeneration through a paracrine mechanism $(40,41)$. Van Buul et al., (42) have reported that BM-MSCs reduce OA pain but without a significant effect on the structural degenerative changes, this difference with the current study results may be attributed to the large dose of MIA that was used to induce OA in their study.

It is to be noted that, we observed that the histopathological improvement was superior in GCSF treated group than BM-MSCs treated group but with no significant difference between the two 
groups. The concomitant administration of G-CSF with BM-MSCs in the combined group showed a highly significant increase in the thickness of AC in comparison to OA group, almost equal to the normal control group, indicating increased matrix density and healthy chondrocyte population on their way to complete recovery from OA injury. The best observed signs of $\mathrm{AC}$ regeneration and absence of cellular apoptosis was obious also in the combined group with an almost normal AC appearance in some sections.

The current study showed that, before MIA injection there were no signs of nociceptor behavior in all groups. MIA caused a highly significant increase in the knee bend scores. These findings are in agreement with previous studies $(43,44)$. In the present study, we found that treatment with BM-MSCs, G-CSF or their combined administration caused improvement in the movement-induced nociceptive behavior and mechanical sensitivity indicated by a decrease in the knee bend scores when compared to OA group at different time points. This improvement in the deep joint pain in affected knee joints mirrors cessation of $\mathrm{OA}$ progression with evolving recovery. Treatment with BM-MSCs caused more decrease in the knee bend score than the two other groups from day 14 till the end of the study.

In this study, Examination of the animal response to the noxious thermal stimuli revealed an increase in hind paw WL after MIA injection with progressive decrease in latency times till the end of the study in all groups including the untreated OA group with no observed thermal hyperalgesia. Numerous previous studies, on the other hand revealed controversial findings as they reported thermal hyperalgesia after MIA administration. Rahman and Dickenson, (45) have suggested that thermal hyperalgesia observed in MIA model of OA is due to the functional alteration in the peripheral nociceptors voltagegated sodium channels which mediate neuroplasticity in OA pain. In agreement with our results, Ruan et al., (46) have declared a significantly delayed response time to thermal stimuli in a cruciate ligament transection mice model of OA compared to sham group. They postulated that their findings are due to either a decrease in the pain sensitivity levels or a motor dysfunction component which may delay an impeding animal response. They also noticed that mice placed more pressure on the toes to decrease the pressure on the hind paw which decrease the contact area between hind paw and the hot plate, an observation that could explain the increase latency time. Another study tested the electrophysiological and behavioral characterization during $\mathrm{OA}$ in mice also reported absence of thermal hypersensitivity throughout their study (47). This controversy among our study findings and other studies may be attributed to one of the previously mentioned justifications in other studies in harmony with ours. It could be also due to the short duration of our study and perhaps the response may be detected late by day 28 or 35 after MIA injection as reported by other authors $(44,48)$.

Regarding this study, MIA caused increased step width and excess hind limb rotation during walking by day 7 post injection. Treatment with BM-MSCs, G-CSF or their combined administration caused a progressive decline in the step width with the loss of the excess limb rotation when compared to the normal group. All the 
treated groups showed a significantly higher stride length when compared with OA group. These findings indicate altered gait pattern with OA. Gait asymmetry in $\mathrm{OA}$ is mainly due to the unilateral compensatory shifting of the applied load over the injured joint to the other unaffected limb aiming to avoid the loading and movement related pain in the affected joint with locking in the range of flexion and extension during walking. These results of disturbed gait in $\mathrm{OA}$ are in agreement with previous studies using MIA model of OA $(31,49,50)$. Lakes and Allen, (32) carried out a quadrupedal gait assessment and observed an early antalgic gait pattern and a shifting toward shufflestepping gait over time which was indicated by a decreased stride length with wider step width. These findings reveal that in OA the animals are walking with shorter steps with broadening their base of support to keep their stability during walking. They also found that forelimbs play a minimal role in compensation during hind limb injury. Concerning the current research, results of the pain analysis and the consequent gait changes, after treatment of $\mathrm{OA}$ with exogenous or endogenously mobilized stem cells are all in agreement of previous studies. This is reflected by improvement in weight bearing and distribution over the affected limb after treatment $(25,42)$, increase in the pain threshold with improved sensitivity to pain (39).

A limitation of this study is that, the dynamics of in vivo stem cell proliferation and mobilization were not tested. In addition, the chondrogenic differentiation of stem cells was not confirmed ex vivo. Although the exact mechanism of anti-nociceptive effect of BM-MSCs is not exactly identified, it may be explained by $\mathrm{AC}$ regeneration occurred and the regain of structural integrity of the joint which combat a chief source of pain in OA. This may be also related to stem cell well-known anti-inflammatory and antiapoptotic effects. The effect of G-CSF is believed to be mediated by an increase in the TLC, which reflect endogenous stem cell mobilization that shared in the healing of the injured tissue.

Collectively, our work sheds light on the promising effect of the mobilized endogenous cells. In addition, the combined effects of endogenous host stem cells and the exogenous cells seems to potentiate the effect of each other and work in a synergistic manner, showing better results than the sole use of each source in the structural recovery, pain sensation and gait improvement. The deep understanding of the underlying mechanisms regarding improvement of the studied parameters remains to be elucidated in future works.

\section{Conflict of interest:}

The authors declare no conflict of interest.

Funding: This research is partially $(10 \%$ of the cost) has been funded by the Suez Canal University Authority.

Author contribution: H.M.: generating the idea of the research, methodology formulation and performing laboratory experiments, searching and editing the methods and scientific background, formulating and discussing of the results in the results and discussion section, and editing of the paper. D.H. \& Sh.Y.: formulation of the idea of the research, methodology formulation, follow up of the experimental procedures and shared in editing the paper. H.E.: performing histopathologic 
assessment, commenting on and editing the histopathological results.

Acknowledgment: Great thanks should be provided for all who contributed to the current work.

\section{References:}

1. Robinson WH, Lepus CM, Wang Q, Raghu H, Mao R, Lindstrom TM, et al. Low-grade inflammation as a key mediator of the pathogenesis of osteoarthritis. Nat Rev Rheumatol. Oct;12(10):580-92, 2016.

2. Kraus VB, Blanco FJ, Englund M, Karsdal MA, Lohmander LS. Call for standardized definitions of osteoarthritis and risk stratification for clinical trials and clinical use. Osteoarthritis Cartilage. Aug;23(8):1233-41, 2015.

3. Vos T, Flaxman AD, Naghavi M, Lozano R, Michaud C, Ezzati M, et al. Years lived with disability (YLDs) for 1160 sequelae of 289 diseases and injuries 1990-2010: a systematic analysis for the Global Burden of Disease Study 2010. Lancet Lond Engl. Dec 15;380(9859):2163-96, 2012.

4. Houard X, Goldring MB, Berenbaum F. Homeostatic mechanisms in articular cartilage and role of inflammation in osteoarthritis. Curr Rheumatol Rep. Nov;15(11):375, 2013.

5. Guzman RE, Evans MG, Bove S, Morenko B, Kilgore K. Mono-iodoacetate-induced histologic changes in subchondral bone and articular cartilage of rat femorotibial joints: an animal model of osteoarthritis. Toxicol Pathol. Dec;31(6):619-24, 2003.

6. Naveen SV, Ahmad RE, Hui WJ, Suhaeb AM, Murali MR, Shanmugam R, et al. Histology, glycosaminoglycan level and cartilage stiffness in monoiodoacetate-induced osteoarthritis: comparative analysis with anterior cruciate ligament transection in rat model and human osteoarthritis. Int $\mathrm{J}$ Med Sci.;11(1):97-105, 2014.

7. Takahashi I, Matsuzaki T, Kuroki H, Hoso M. Induction of osteoarthritis by injecting monosodium iodoacetate into the patellofemoral joint of an experimental rat model. PLOS ONE. Apr 26;13(4):e0196625, 2018.

8. Zhang W, Ouyang H, Dass CR, Xu J. Current research on pharmacologic and regenerative therapies for osteoarthritis. Bone Res.;4:15040, 2016.

9. McAlindon TE, Bannuru RR, Sullivan MC, Arden NK, Berenbaum F, Bierma-Zeinstra SM, et al. OARSI guidelines for the nonsurgical management of knee osteoarthritis. Osteoarthritis Cartilage. Mar;22(3):363-88, 2014.

10. Counsel PD, Bates D, Boyd R, Connell DA. Cell therapy in joint disorders. Sports Health.;7(1):27-37, 2015.

11. Cucchiarini M, Madry H. Biomaterialguided delivery of gene vectors for targeted articular cartilage repair. Nat Rev Rheumatol. Dec 4;1, 2018.

12. Madry H, Cucchiarini M. Gene therapy for human osteoarthritis: principles and clinical translation. Expert Opin Biol Ther.;16(3):33146, 2016.

13. Mobasheri A, Kalamegam G, Musumeci G, Batt ME. Chondrocyte and mesenchymal stem cell-based therapies for cartilage repair in osteoarthritis and related orthopaedic conditions. Maturitas.;78(3):188-98, 2014. 
14. Vinatier C, Bouffi C, Merceron C, Gordeladze J, Brondello J-M, Jorgensen C, et al. Cartilage tissue engineering: towards a biomaterial-assisted mesenchymal stem cell therapy. Curr Stem Cell Res Ther. Dec;4(4):318-29, 2009.

15. Sakaguchi Y, Sekiya I, Yagishita K, Muneta

T. Comparison of human stem cells derived from various mesenchymal tissues: superiority of synovium as a cell source. Arthritis Rheum. Aug;52(8):2521-9, 2005.

16. Wolfstadt JI, Cole BJ, Ogilvie-Harris DJ, Viswanathan S, Chahal J. Current concepts: the role of mesenchymal stem cells in the management of knee osteoarthritis. Sports Health. Jan;7(1):38-44, 2015.

17. Brouard N, Driessen R, Short B, Simmons

PJ. G-CSF increases mesenchymal precursor cell numbers in the bone marrow via an indirect mechanism involving osteoclastmediated bone resorption. Stem Cell Res. Jul;5(1):65-75, 2010.

18. Deng J, Zou Z, Zhou T, Su Y, Ai G, Wang $\mathbf{J}$, et al. Bone marrow mesenchymal stem cells can be mobilized into peripheral blood by GCSF in vivo and integrate into traumatically injured cerebral tissue. Neurol Sci Off J Ital Neurol Soc Ital Soc Clin Neurophysiol. Aug;32(4):641-51, 2011.

19. Fu W-L, Zhou C-Y, Yu J-K. A new source of mesenchymal stem cells for articular cartilage repair: MSCs derived from mobilized peripheral blood share similar biological characteristics in vitro and chondrogenesis in vivo as MSCs from bone marrow in a rabbit model. Am J Sports Med. Mar;42(3):592-601, 2014.
20. Abaei M, Sagar DR, Stockley EG, Spicer CH, Prior M, Chapman V, et al. Neural correlates of hyperalgesia in the monosodium iodoacetate model of osteoarthritis pain. Mol Pain.;12, 2016.

21. Kelly S, Dobson KL, Harris J. Spinal nociceptive reflexes are sensitized in the monosodium iodoacetate model of osteoarthritis pain in the rat. Osteoarthritis Cartilage. Sep;21(9):1327-35, 2013.

22. More AS, Kumari RR, Gupta G, Lingaraju MC, Balaganur V, Pathak NN, et al. Effect of iNOS inhibitor S-methylisothiourea in monosodium iodoacetate-induced osteoathritic pain: implication for osteoarthritis therapy. Pharmacol Biochem Behav. Feb;103(4):76472, 2013.

23. Ross D, Maerz T, Kurdziel M, Hein J, Doshi S, Bedi A, et al. The effect of granulocytecolony stimulating factor on rotator cuff healing after injury and repair. Clin Orthop. May;473(5):1655-64, 2015.

24. Okano T, Mera H, Itokazu M, Okabe T, Koike T, Nakamura H, et al. Systemic Administration of Granulocyte ColonyStimulating Factor for Osteochondral Defect Repair in a Rat Experimental Model. Cartilage. Apr;5(2):107-13, 2014.

25. Buul GM van, Siebelt M, Leijs MJ, Bos P, Waarsing JH, Kops N, et al. Mesenchymal stem cell therapy in a rat model of osteoarthritis. Osteoarthritis Cartilage. Apr 1;20:S275, 2012.

26. Soleimani M, Nadri S. A protocol for isolation and culture of mesenchymal stem cells from mouse bone marrow. Nat Protoc.;4(1):102-6, 2009. 
27. Roeder E, Henrionnet C, Goebel JC, Gambier N, Beuf O, Grenier D, et al. Doseresponse of superparamagnetic iron oxide labeling on mesenchymal stem cells chondrogenic differentiation: a multi-scale in vitro study. PloS One.;9(5):e98451, 2014.

28. Silva A, Andersen ML, Tufik S. Sleep pattern in an experimental model of osteoarthritis. Pain. Dec;140(3):446-55, 2008.

29. Boettger MK, Weber K, Schmidt M, Gajda M, Bräuer R, Schaible H-G. Gait abnormalities differentially indicate pain or structural joint damage in monoarticular antigen-induced arthritis. Pain. Sep;145(12):142-50, 2009.

30. Morais SV de, Czeczko NG, Malafaia $\mathbf{O}$, Ribas JM, Garcia JBS, Miguel MT, et al. Osteoarthritis model induced by intra-articular monosodium iodoacetate in rats knee. Acta Cir Bras. Nov;31(11):765-73, 2016.

31. Ishikawa G, Nagakura Y, Takeshita N, Shimizu Y. Efficacy of drugs with different mechanisms of action in relieving spontaneous pain at rest and during movement in a rat model of osteoarthritis. Eur J Pharmacol.;738:111-7, 2014.

32. Lakes EH, Allen KD. Quadrupedal rodent gait compensations in a low dose monoiodoacetate model of osteoarthritis. Gait Posture.;63:73-9, 2018.

33. Okano T, Mera H, Itokazu M, Okabe T, Koike T, Nakamura $\mathbf{H}$, et al. Systemic Administration of Granulocyte ColonyStimulating Factor for Osteochondral Defect Repair in a Rat Experimental Model. Cartilage. Apr;5(2):107-13, 2014.
34. Sasaki T, Akagi R, Akatsu Y, Fukawa T, Hoshi H, Yamamoto Y, et al. The effect of systemic administration of G-CSF on a fullthickness cartilage defect in a rabbit model MSC proliferation as presumed mechanism: G-CSF for cartilage repair. Bone Jt Res. Mar;6(3):123-31, 2017.

35. Fu W-L, Zhou C-Y, Yu J-K. A new source of mesenchymal stem cells for articular cartilage repair: MSCs derived from mobilized peripheral blood share similar biological characteristics in vitro and chondrogenesis in vivo as MSCs from bone marrow in a rabbit model. Am J Sports Med. Mar;42(3):592-601, 2014.

36. Ali SM, Okda AAK, Dessouky IS, Hewedy WA, Zahran NM, Alamrani BA. L-Carnitine ameliorates knee lesions in mono-iodoacetate induced osteoarthritis in rats. Alex J Med.;53(1):61-6, 2017.

37. Osman WA, Elmessiry SAEM, Shaker OG, Zaki IM, Wissa MY, Amer MS, et al. Comparative study of the effect of diacerein and diclofenac sodium and their combination in osteoarthritis model induced by monoiodoacetate in albino rats. Res J Pharm Biol Chem Sci.;6(3):1079-89, 2015.

38. Yang X, Zhu T-Y, Wen L-C, Cao Y-P, Liu C, Cui Y-P, et al. Intraarticular Injection of Allogenic Mesenchymal Stem Cells has a Protective Role for the Osteoarthritis. Chin Med J (Engl). Sep 20;128(18):2516-23, 2015.

39. Gupta PK, Chullikana A, Rengasamy M, Shetty N, Pandey V, Agarwal V, et al. Efficacy and safety of adult human bone marrow-derived, cultured, pooled, allogeneic mesenchymal stromal cells (Stempeucel ${ }^{\circledR}$ ): 
preclinical and clinical trial in osteoarthritis of the knee joint. Arthritis Res Ther [Internet]. 2016 [cited 2018 Dec 12];18. Available from: https://www.ncbi.nlm.nih.gov/pmc/articles/PM C5168586/

40. Guo W, Wang H, Zou S, Gu M, Watanabe M, Wei F, et al. Bone Marrow Stromal Cells Produce Long-Term Pain Relief in Rat Models of Persistent Pain. Stem Cells Dayt Ohio. Aug;29(8):1294-303, 2011.

41. Gupta PK, Das AK, Chullikana A, Majumdar AS. Mesenchymal stem cells for cartilage repair in osteoarthritis. Stem Cell Res Ther. Jul 9;3(4):25, 2012.

42. van Buul GM, Siebelt M, Leijs MJC, Bos PK, Waarsing JH, Kops $\mathrm{N}$, et al. Mesenchymal stem cells reduce pain but not degenerative changes in a mono-iodoacetate rat model of osteoarthritis. J Orthop Res Off Publ Orthop Res Soc. Sep;32(9):1167-74, 2014.

43. Ferreira-Gomes J, Adães S, Mendonça M, Castro-Lopes JM. Analgesic effects of lidocaine, morphine and diclofenac on movement-induced nociception, as assessed by the Knee-Bend and CatWalk tests in a rat model of osteoarthritis. Pharmacol Biochem Behav. Jun;101(4):617-24, 2012.

44. Im H-J, Kim J, Li X, Kotwal N, Sumner DR, van Wijnen AJ, et al. Alteration of Sensory Neurons and Spinal Response To An Experimental Osteoarthritis Pain Model. Arthritis Rheum. Oct;62(10):2995-3005, 2010.
45. Rahman W, Dickenson AH. Antinociceptive effects of lacosamide on spinal neuronal and behavioural measures of pain in a rat model of osteoarthritis. Arthritis Res Ther. Dec 23;16(6):509, 2014.

46. Ruan MZC, Patel RM, Dawson BC, Jiang M-M, Lee BHL. Pain, motor and gait assessment of murine osteoarthritis in a cruciate ligament transection model. Osteoarthritis Cartilage. Sep;21(9):1355-64, 2013.

47. Harvey VL, Dickenson AH. Behavioural and electrophysiological characterisation of experimentally induced osteoarthritis and neuropathy in C57B1/6 mice. Mol Pain. Apr 20;5:18, 2009 .

48. Liu P, Okun A, Ren J, Guo R, Ossipov MH, Xie $\mathbf{J}$, et al. Ongoing pain in the MIA model of osteoarthritis. Neurosci Lett. Apr 15;493(3):72-5, 2011.

49. Ferland CE, Laverty S, Beaudry F, Vachon P. Gait analysis and pain response of two rodent models of osteoarthritis. Pharmacol Biochem Behav. Jan;97(3):603-10, 2011.

50. Jacobs BY, Dunnigan K, Pires-Fernandes M, Allen KD. Unique spatiotemporal and dynamic gait compensations in the rat monoiodoacetate injection and medial meniscus transection models of knee osteoarthritis. Osteoarthritis Cartilage.;25(5):750-8, 2017 